\title{
Excessive daytime sleepiness as cardiovascular risk in Croatian obese patients
}

\author{
(DFilip Mustač ${ }^{*}$, \\ (D) Martina Matovinović ${ }^{2}$, \\ (DTomislav Mutak', \\ (DBarbara Barun², \\ (D) Juraj Jug', \\ (D) Rea Levicki ${ }^{3}$, \\ (D) Martina Lovrić \\ Benčić1,2 \\ DAna Jelaković ${ }^{2}$, \\ (DBojan Jelaković ${ }^{1,2}$ \\ 'University of Zagreb School \\ of Medicine, Zagreb, Croatia \\ 2University of Zagreb School \\ of Medicine, University \\ Hospital Centre Zagreb, \\ Zagreb, Croatia \\ ${ }^{3}$ Požega General County \\ Hospital, Požega, Croatia
}

KEYWORDS: excessive daytime sleepiness, cardiovascular risk, obesity, hypertension. CITATION: Cardiol Croat. 2019;14(9-10):236. | https://doi.org/10.15836/ccar2019.236

*ADDRESS FOR CORRESPONDENCE: Filip Mustač, Susedgradska 3, HR-10000 Zagreb, Croatia. / Phone: +385-919232-406 / E-mail: filip.mustac@gmail.com

ORCID: Filip Mustač, https://orcid.org/0000-0003-2851-6183 • Martina Matovinović, https://orcid.org/0000-0002-6325-7394 Tomislav Mutak, https://orcid.org/0000-0002-2791-1379 • Barbara Barun, https://orcid.org/0000-0002-1665-7491 Juraj Jug, https://orcid.org/0000-0002-3189-1518 • Rea Levicki, https://orcid.org/0000-0003-3687-1310

Martina Lovrić Benčić, https://orcid.org/0000-0001-8446-6120 • Ana Jelaković, https://orcid.org/0000-0002-9262-4667 Bojan Jelaković, https://orcid.org/0000-0002-2546-4632

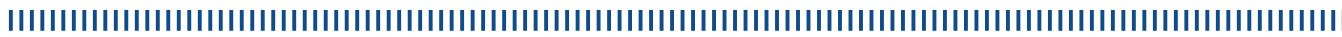

Introduction: Excessive daytime sleepiness (EDS) is a very common complaint, especially in obese patients and is a potentially alarming symptom related to many risk factors and comorbidities ${ }^{1}$. In obese patients obstructive sleep apnea (OSA) is quite common. Our goal was to assess the connection between EDS and hypertension in Croatian obese patients

Patients and Methods: This cross-sectional study was carried out in a tertiary healthcare centre in an outpatient clinic for treatment of obesity. 49 participants were included. Inclusion criterion was BMI $>30 \mathrm{~kg} / \mathrm{m}^{2}$ Epworth Sleepiness Scale (ESS), consisting of 8 questions, every question ranged from 0-3 (overall range 0-24) was used to assess EDS. Spearman correlation coefficient, Welch t-test, chi-squared test and regression analysis were used. They were divided into 4 and 3 categories. 4 categories: 0-7, 8-9, 10-15 and 16-24. Many researches take ESS score 10 or greater as excessive daytime sleepiness, so our results were also interpreted as 3 categories: 0-7, 8-9 and 10 or greater.

Results: Mean age of our participants was $50.29 \pm 11.91$ years. Overall mean BMI was $44.64 \pm 8.12 \mathrm{~kg} / \mathrm{m}^{2}$. Results on ESS divided into 4 categories (Figure 1) were statistically significant correlated to hypertension: $\mathrm{x}^{2}=9.61$ $\mathrm{p}=.02$. Also, results on ESS in 3 categories (Figure 2) were statistically significant correlated to hypertension: $x^{2}(2)=9.43 ; p=.009$. Results on ESS were not significantly connected to AHI index (ESS in 4 categories:

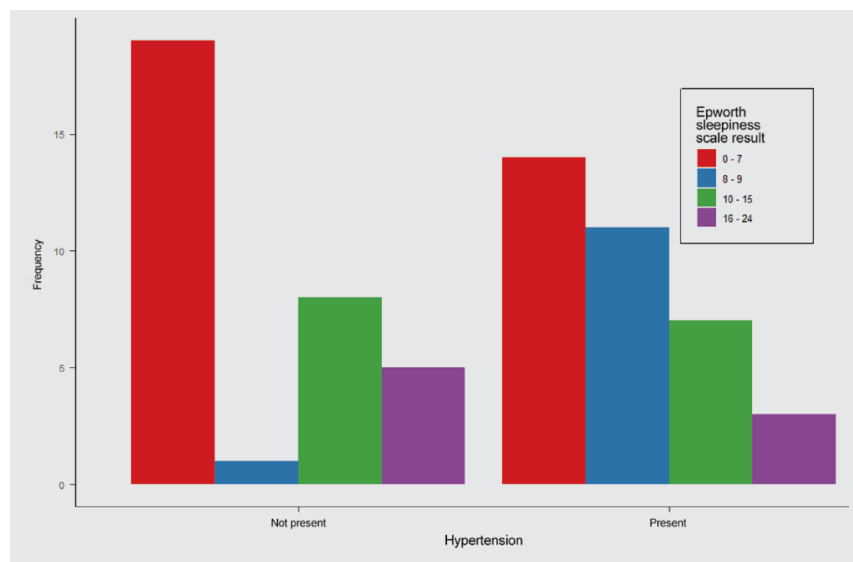

FIGURE 1. Scores on Epworth Sleepiness Scale divided into 4 categories depending on the presence of hypertension.

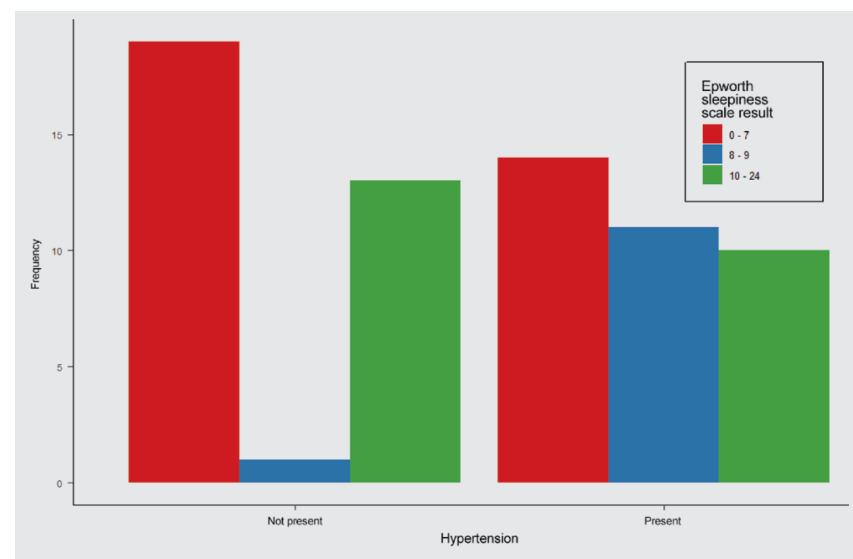

FIGURE 2. Scores on Epworth Sleepiness Scale divided into 3 categories depending on the presence of hypertension.
RECEIVED:

August 5, 2019

ACCEPTED:

September 16, 2019

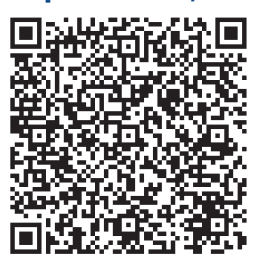

$\square$ Cardiologia Croatica 2019;14(9-10):236 $x^{2}(9)=8.43, p=.49 ;$ ESS in 3 categories : $\left.x^{2}(6)=6.45, p=.37\right)$. Furthermore, results on ESS were not correlated to sex (ESS in 4 categories $x^{2}(3)=0.85, p=.84$ and ESS in 3 categories: $x^{2}(2)=0.56, p=.76$ ).

Conclusion: Our results show that the presence of hypertension alters the result on the ESS and is most visible in the so-called "borderline" area for the ESS score 8-9 in both divisions (into 3 and 4 categories), which shows a possible underestimation of the risk of the population achieving the result on the ESS $<10$, which is consistent with the studies of Borsini et al. ${ }^{2}$

LITERATURE IIIIIIIIIIIIIIIIIIIIIIIIIIIIIIIIIIIIIIIIIIIIIIIIIIIIIIIIIIIIIIIIIIIIIIIIIIIIIIIIIIIIIIIIIIIIIIIIIIIIIIII

1. Boyes J, Drakatos P, Jarrold I, Smith J, Steier J. The use of an online Epworth Sleepiness Scale to assess excessive daytime sleepiness. Sleep Breath. 2017 May;21(2):333-340. https://doi.org/10.1007//11325-016-1417-x

2. Borsini E, Blanco M, Bosio M, Schrappe M, Ernst G, Nosetto D, et al. Prevalence of sleep apnea and cardiovascular risk factors in patients with hypertension in a day hospital model. Clin Exp Hypertens. 2018;40(3):231-237. https://doi.org/10.1080/10641963.2017.1356841 